\title{
Scaffold-like 3D networks fabricated via the organogelation of $\beta$-diketone-boron for fluorescent sensing organic amine vapors
}

\author{
QIAN Chong, CAO KaiYu, LIU XingLiang, ZHANG XiaoFei, XU DeFang, \\ XUE PengChong \& LU Ran*
}

State Key Laboratory of Supramolecular Structure and Materials, College of Chemistry, Jilin University, Changchun 130012, China

Received April 8, 2012; accepted May 28, 2012; published online September 14, 2012

\begin{abstract}
A new compoud based on carbazole functionalized $\beta$-diketone-boron difluoride (1) was synthesized. It is found that compoud $\mathbf{1}$ can gel toluene, ethylbenzene and some mixed solvents, and 3D networks consisting lots of nanofibers were observed using SEM and fluorescence microscopy. The molecular packing model in xerogel $\mathbf{1}$ was proposed according to the results of XRD, UV/Vis absorption and semiempirical calculations. The obtained nanofibers prepared through organogelation can emit strong orange light under irradiation. It is interesting that the fluorescence of the nanofiber-based film can be quenched quickly and significantly upon exposed to the vapors of $n$-butylamine, dibutylamine, triethylamine, triethylamine, cyclohexylamine, aniline and pyridine instead of other common reagents. Notably, the response time of the nanofiber-based film to aniline vapor reached ca. $0.59 \mathrm{~s}$, and the detection limit for aniline was as low as ca. $0.83 \mathrm{~mL} / \mathrm{m}^{3}$.
\end{abstract}

$\pi$-organogel, $\beta$-diketone-boron difluoride, fluorescent sensing, organic amine vapors

Citation: Qian C, Cao K Y, Liu X L, et al. Scaffold-like 3D networks fabricated via the organogelation of $\beta$-diketone-boron for fluorescent sensing organic amine vapors. Chin Sci Bull, 2012, 57: 4264-4271, doi: 10.1007/s11434-012-5454-y

Detection of volatile organic amines is of great interest in the fields of environmental and industrial monitoring [1,2], quality control of food [3-5], and medical diagnosis of certain types of disease [6-8]. For example, $5 \mathrm{~mL} / \mathrm{m}^{3}$ is the recommended threshold for human exposure to the primary irritants butylamine and isopropylamine. In addition, some biogenic amines are found to be released from certain diseases like uremia and lung cancer [7,8]. So far, many approaches for detecting organic amines, such as electrochemical devices [9-11], ion selective electrodes [12], and chemical sensors [13-16], have been employed. However, fluorescent sensor has proved to be an expedient detection technique on account of the high signal output and detection simplicity. Recently, Zang and co-workers [17,18] have reported an expedient sensor based on fluorescent nanofibers fabricated from an n-type organic semiconductor for detecting organic amine vapors. Mohr et al. [19,20] have employed fluorescent dye-based membranes for probing

*Corresponding author (email: luran@mail.jlu.edu.cn) lipophilic primary amines via reversible chemical reactions with high sensitivity and selectivity. Fang and co-workers [21] have reported an ultrasensitive fluorescent sensing nanofilm based on cholesterol-modified perylene bisimide for detecting organic amines. Till now, fluorescent sensing trace volatile amines is still challenging due to the limitation of the organic dyes-based films with intense emission, as well as rapid, sensitive response to amine vapors.

It is known that $\beta$-diketone-boron difluorides are typical fluorescent dyes with high fluorescence quantum yields [22], large molar extinction coefficients [23] and high electron mobilities [24]. In particular, our group have fabricated 1D nanofibers with intense emission from bis( $\beta$-diketone) triphenylamines [25-28], and they can be used as sensory materials for detecting organic amine vapors with high sensitivity and fast response, which are originated from the high surface-to-volume ratio and large interspace in $3 \mathrm{D}$ networks consisting of lots of nanofibrils as well as the amplified fluorescence quenching induced by the enhanced intermolecular exciton diffusion along the long axis of the 
1D nanostructures. In addition, we have found that the conjugated molecules with $\mathrm{V}$-shaped $\pi$-skeleton prefer to form organogels [25,27-31], and the fluorescent organogel nanofibers-based films could become good candidate in sensory materials. With this in mind, we intend to design a new organogelator based on $\beta$-diketone-boron difluorides in $\mathrm{V}$-shape to construct emitting organogel nanofibers. As shown in Scheme 1, a carbazole functionalized $\beta$-diketoneboron difluorides 1 was synthesized. It has been found that the fluorescence emission of the nanofibers-based film can be quenched quickly and significantly upon exposure to various gaseous amines, including $n$-butylamine, dibutylamine, diethylamine, triethylamine, cyclohexylamine and aniline, etc. Taking aniline vapor as an example, the detection limit of the nanofiber-based film reaches ca. 0.83 $\mathrm{mL} / \mathrm{m}^{3}$, and the response time is ca. $0.59 \mathrm{~s}$. Therefore, the organogelation of fluorescent $\pi$-gelators has been further confirmed to be a facile way to generate chemosensors with high performance.

\section{Experimental}

\subsection{Materials}

THF were freshly distilled from sodium and benzophenone. $\mathrm{CH}_{2} \mathrm{Cl}_{2}$ was distilled from $\mathrm{CaH}_{2}$. Other chemicals were used as received. The synthetic routes for compounds $\mathbf{1}$ were shown in Scheme 1.

3-acetyl-9-( $n$-hexadecyl)-carbazole (2): 3-acetyl-9-( $n$ hexadecyl)-carbazole was prepared according to the previously reported methods [32]. $\mathrm{AlCl}_{3}(2.0 \mathrm{~g}, 15.4 \mathrm{mmol})$ was added to the solution of $\mathrm{N}$ - $(n$-hexadecyl)-carbazole $(3.0 \mathrm{~g}$, $7.7 \mathrm{mmol})$ in anhydrous $\mathrm{CH}_{2} \mathrm{Cl}_{2}(50 \mathrm{~mL})$ quickly with stirring in ice bath. When the mixture was cooled to $0^{\circ} \mathrm{C}$, the solution of acetic anhydride $(0.79 \mathrm{~g}, 7.7 \mathrm{mmol})$ in $\mathrm{CH}_{2} \mathrm{Cl}_{2}$ $(10 \mathrm{~mL})$ was added dropwise via syringe under vigorous stirring. After that, the ice bath was removed, and the dark green slurry solution was warmed to room temperature with stirring over night. Then, the mixture was poured into a mixture of ice and concentrated $\mathrm{HCl}$. After extracted with $\mathrm{CH}_{2} \mathrm{Cl}_{2}$ for three times, the organic phase was combined and dried over $\mathrm{MgSO}_{4}$. Removing the solvent under reduced pressure, the residue was purified by chromatography on silica gel using petroleum/ $\mathrm{CH}_{2} \mathrm{Cl}_{2}(\mathrm{v} / \mathrm{v}=1 / 2)$ as eluent, giving $2.1 \mathrm{~g}$ compound 2 as a white solid. Yield: $63 \%$, m.p. $=56-58^{\circ} \mathrm{C} .{ }^{1} \mathrm{H}$ NMR $\left(\mathrm{CDCl}_{3}, 500 \mathrm{MHz}\right), \delta=$ $8.75(1 \mathrm{H}, \mathrm{d}, J=1.5 \mathrm{~Hz}), 8.16(1 \mathrm{H}, \mathrm{d}, J=8 \mathrm{~Hz}), 8.14-8.12$ (1 H, m), 7.53-7.50 (1 H, m), $7.44(1 \mathrm{H}, \mathrm{d}, J=8 \mathrm{~Hz}), 7.41$ $(1 \mathrm{H}, \mathrm{d}, J=9 \mathrm{~Hz}), 7.3(1 \mathrm{H}, \mathrm{t}, J=7.5 \mathrm{~Hz}, J=7.5 \mathrm{~Hz}), 4.32$ $(2 \mathrm{H}, \mathrm{t}, J=6 \mathrm{~Hz}, J=7.5 \mathrm{~Hz}), 2.73(3 \mathrm{H}, \mathrm{s}), 1.91-1.85(2 \mathrm{H}$, $\mathrm{m}), 1.40-1.23(26 \mathrm{H}, \mathrm{m}), 0.88(3 \mathrm{H}, \mathrm{t}, J=6.5 \mathrm{~Hz}, J=7 \mathrm{~Hz})$. FT-IR $\left(\mathrm{cm}^{-1}\right)$ : 3440, 2920, 2850, 1670, 1590, 1470, 1360, and 1250. A strong peek at $1670 \mathrm{~cm}^{-1}$ is the $v_{\mathrm{s}}$ of $\mathrm{C}=\mathrm{O}$ moiety. MALDI-TOF MS, $m / z$ (\%): Calcd. 433.3, found 434.1 (100) $[\mathrm{M}]^{+}$. Elemental analysis for $\mathrm{C}_{30} \mathrm{H}_{43} \mathrm{NO}$ : Calcd. (\%) $\mathrm{C}$, 83.09; H, 9.99; N, 3.23; O, 3.69. Found (\%): C, 82.86; H, $9.80 ; \mathrm{N}, 3.11$.

$m$-Bis((4,4'-(9-(n-hexadecyl)-9H-carbazol-3-yl))-2,2'-difl uoro-1,3,2-dioxaborine)-benzene (1): Dimethyl isophthalate $(0.20 \mathrm{~g}, 1 \mathrm{mmol})$ and compound $2(0.98 \mathrm{~g}, 2.2 \mathrm{mmol})$ were dissolved in dry THF $(50 \mathrm{~mL})$ under an atmosphere of nitrogen. Then, $\mathrm{NaH}(0.5 \mathrm{~g}, 12.5 \mathrm{mmol})$ was added to the solution. The mixture was stirred at $60^{\circ} \mathrm{C}$ for $24 \mathrm{~h}$, followed by poured into ice water $(300 \mathrm{~mL}) . \mathrm{HCl}(6 \mathrm{~mol} / \mathrm{L}, 10 \mathrm{~mL})$ was added to neutralize excess $\mathrm{NaH}$. After that, the mixture was extracted with $\mathrm{CH}_{2} \mathrm{Cl}_{2}$ for three times, and the organic phase was combined and dried over sodium sulfate. After removal of solvent, the residue was used directly in the next step without purification. Then, the solution of $m$-bis $((4$, 4'-(9-(n-hexadecyl)-9H-carbazol-3-yl))-propan-1,3-dione)benzene in dry $\mathrm{CH}_{2} \mathrm{Cl}_{2}(50 \mathrm{~mL})$ was heated to reflux under an atmosphere of nitrogen, and excess $\mathrm{BF}_{3} \cdot \mathrm{Et}_{2} \mathrm{O}(0.5 \mathrm{~mL})$ was added. The mixture was refluxed for $12 \mathrm{~h}$. After the solvent was removed, the residue was purified by column chromatography using petroleum ether/ $\mathrm{CH}_{2} \mathrm{Cl}_{2}(1 / 3, \mathrm{v} / \mathrm{v})$ as eluent, followed by recrystallization twice from the mixed solvent of ethanol and tetrahydrofuran to afford compound $1(0.36 \mathrm{~g})$ as an orange solid. Yield: $32 \%$, m.p. $>200^{\circ} \mathrm{C} .{ }^{1} \mathrm{H}$ $\operatorname{NMR}\left(\mathrm{CDCl}_{3}, 500 \mathrm{MHz}\right), \delta=8.83(2 \mathrm{H}, \mathrm{s}), 8.57(1 \mathrm{H}, \mathrm{s})$, $8.31(2 \mathrm{H}, \mathrm{d}, J=8 \mathrm{~Hz}), 8.21(2 \mathrm{H}, \mathrm{d}, J=9 \mathrm{~Hz}), 8.13(2 \mathrm{H}, \mathrm{d}$, $J=8 \mathrm{~Hz}), 7.69(1 \mathrm{H}, \mathrm{t}, J=8 \mathrm{~Hz}, J=7.5 \mathrm{~Hz}), 7.53(2 \mathrm{H}, \mathrm{t}, J$ $=7.5 \mathrm{~Hz}, J=7.5 \mathrm{~Hz}), 7.40-7.32(8 \mathrm{H}, \mathrm{m}), 4.16(4 \mathrm{H}, \mathrm{t}, J=$ $7 \mathrm{~Hz}, J=7.5 \mathrm{~Hz}), 1.87-1.81(4 \mathrm{H}, \mathrm{m}), 1.38-1.26(52 \mathrm{H}, \mathrm{m})$, $0.90(6 \mathrm{H}, \mathrm{t}, J=6 \mathrm{~Hz}, J=7.5 \mathrm{~Hz}) .{ }^{13} \mathrm{C} \mathrm{NMR}\left(\mathrm{CDCl}_{3}, 125\right.$

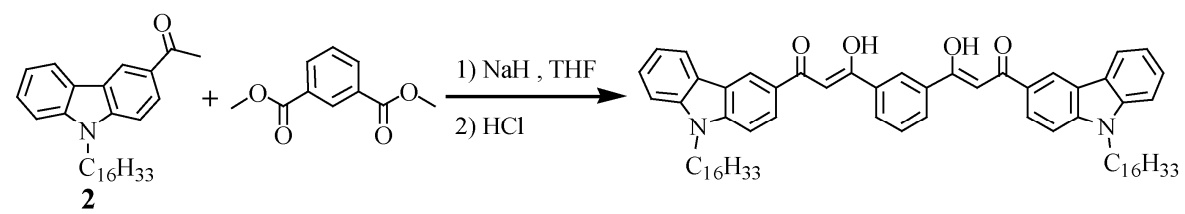

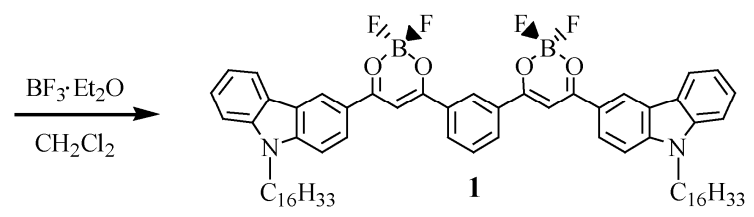

Scheme 1 The synthetic routes for compound 1. 
$\mathrm{MHz})$ : 183.18, 177.29, 144.92, 141.01, 133.41, 132.94, $129.54,127.56,127.29,127.10,123.44,123.41,122.77$, 121.50, 121.04, 109.58, 108.98, 92.93, 43.38, 31.93, 29.70, $29.66,29.62,29.58,29.51,29.36,29.33,28.87,27.24$, 22.70, 14.12. FT-IR (KBr, cm $\left.{ }^{-1}\right): 2920,2850,2360,1540$, 1470, 1360, 1030. MALDI-TOF MS, $\mathrm{m} / z$ (\%): Calcd. 1093.0, found $1074.3(100)[\mathrm{M}-\mathrm{F}]^{+}, 1093.4(18)\left[\mathrm{M}^{+}, 1116.3(56)\right.$ $[\mathrm{M}+\mathrm{Na}]^{+}, \quad 1132.6(76)[\mathrm{M}+\mathrm{K}]^{+}$. Elemental analysis for $\mathrm{C}_{68} \mathrm{H}_{86} \mathrm{~B}_{2} \mathrm{~F}_{4} \mathrm{~N}_{2} \mathrm{O}_{4}$ : Calcd. (\%) C, 74.72; H, 7.93; B, 1.98; F, 6.95; N, 2.56; O, 5.86. Found (\%): C, 74.54; H, 7.75; N, 2.42.

\subsection{Measurements and characterization}

${ }^{1} \mathrm{H}$ and ${ }^{13} \mathrm{C}$ NMR spectra were recorded with a Mercury plus instrument at 500 and $125 \mathrm{MHz}$ by using $\mathrm{CDCl}_{3}$ as the solvent. FT-IR spectra were measured with a Nicolet-360 FTIR spectrometer by incorporation of samples in $\mathrm{KBr}$ disks. UV/Vis absorption spectra were determined with a Shimadzu UV-1601PC spectrophotometer. Photoluminescence (PL) spectra were carried out with a Shimadzu RF-5301 luminescence spectrometer. Mass spectra were performed with Agilent $1100 \mathrm{MS}$ series and AXIMA CFR MALDITOF (matrix-assisted laser desorption ionization/time-offlight) MS (COMPACT). C, $\mathrm{H}$ and $\mathrm{N}$ elemental analyses were taken with a Perkin-Elmer 240C elemental analyzer. Scanning electron microscopy (SEM) was performed on JEOL JSM-6700F (operating at $5 \mathrm{kV}$ ). The samples were prepared by casting the organogel on silicon wafers and dried at room temperature, followed by coating with gold. Fluorescence microscopy images were taken on Fluorescence Microscope (Olympus Reflected Fluorescence System BX51, Olympus, Japan). X-ray Diffraction patterns were obtained using Shimadazu XRD-6000 diffractometer with $\mathrm{Cu} \mathrm{K} \alpha$ radiation $(\lambda=1.5418 \AA)$, employing a scanning rate of $0.02^{\circ} \mathrm{s}^{-1}$ in the $2 \theta$ range from $2^{\circ}$ to $30^{\circ}$. The samples for fluorescence microscopy and XRD measurements were prepared by casting the gel in ethylbenzene on glass slide and dried at room temperature. The thickness of the film was measured using Veeco Dektak 150 Surface Profiler.

\subsection{Preparation of the nanofibers-based films for micro- scopy characterization and sensory investigations}

A clear solution of $\mathbf{1}$ in ethylbenzene was obtained by heating. After the hot solution was suffered a sonification for $30 \mathrm{~s}$, followed by aging for $10 \mathrm{~min}$ at room temperature, the gel was formed. After diluting the gel into a "poor" solvent of ethanol, well-dispersed nanofibers were produced. The mesh-like films were fabricated after casting the nanofibers in ethanol onto the substrates, followed by the natural evaporation of the solvent. The thickness of the films was ca. $800 \mathrm{~nm}$ on average.

The sensory investigations for the films based on the nanofibers of 1 were carried out at $25^{\circ} \mathrm{C}$. Firstly, the organic amine vapors and other analytes at a certain concentration were obtained by diluting the saturated vapors with nitrogen, and then injecting them into a quartz cell (10 $\mathrm{mm}$ in width) containing the film. The time-dependent fluorescence spectra and the changes in the emission intensity at $600 \mathrm{~nm}$ were recorded after injection of the organic amine or other interference vapors for $5 \mathrm{~s}$. For the detection of the saturated aniline vapor, a cotton gauze saturated with aniline was placed in the bottom of a quartz cell (10 $\mathrm{mm}$ in width) with a cap to prevent the direct contact of the film with aniline and to maintain a constant vapor pressure. Then, the glass slide, which was coated with the prepared nanofibers, was put in the cell quickly, and the time-dependent fluorescence spectra and the changes in the emission intensity at $600 \mathrm{~nm}$ were recorded.

\section{Results and discussion}

\subsection{Synthesis and characterization}

The synthetic route for compound $\mathbf{1}$ was shown in scheme 1. Firstly, Claisen condensation between dimethyl isophthalate and compound $\mathbf{2}$, which was synthesized from 3-acetyl-9-(n-hexadecyl)-carbazole under Friedel-Crafts acylation condition, in the presence of sodium hydride in anhydrous THF yield $m$-bis((4,4'-(9-(n-hexadecyl)-9Hcarbazol-3-yl))-propan-1,3-dione)-benzene. Then, the intermediate without purification was complexed with boron trifluoride-diethyl etherate in anhydrous $\mathrm{CH}_{2} \mathrm{Cl}_{2}$. Compound 1 was obtained in a yield of $32 \%$ over two steps, and was characterized by ${ }^{1} \mathrm{H}$ NMR, and FTIR spectroscopy, MALDI-TOF mass spectrometry, and $\mathrm{C}, \mathrm{H}, \mathrm{N}$ elemental analyses.

\subsection{Gelation behavior of compound 1}

The gelation property of $\mathbf{1}$ was tested in various solvents by means of the "stable to inversion of a test tube" method [33]. As summarized in Table 1, we found that $\mathbf{1}$ was readily dissolved in 1,2-dichloroethane, dichloromethane, THF, DMF, DMSO, benzene and chlorobenzene, but insoluble in aliphatic hydrocarbon solvents and lower alcohols, and precipitated in ethyl acetate and acetone. However, it can form organogels in toluene, ethylbenzene and the mixed solvents of toluene/cyclohexane $(2 / 1, \mathrm{v} / \mathrm{v})$, toluene/n-heptane $(3 / 1$, $\mathrm{v} / \mathrm{v})$ under ultrasound stimulation instead of a heatingcooling process. The critical gelation concentration (CGC) varied in the range of $2.8-5.0 \mathrm{mmol} / \mathrm{L}$ depending on the solvents. In addition, the obtained gels were stable for several weeks at room temperature.

\subsection{Photophysical properties}

The UV/Vis absorption and the fluorescence emission spectra of compound $\mathbf{1}$ in solution with different polarity are shown in Figure 1. The absorption band appeared at $345 \mathrm{~nm}$ 
Table 1 Gelation properties of $\mathbf{1}$ in selected organic solvents ${ }^{\text {a) }}$

\begin{tabular}{|c|c|}
\hline Solvent & Compound 1 (CGC) \\
\hline Ethyl acetate & $\mathrm{P}$ \\
\hline Acetone & $\mathrm{P}$ \\
\hline 1,2-Dichloroethane & $\mathrm{S}$ \\
\hline Dichloromethane & $\mathrm{S}$ \\
\hline THF & $\mathrm{S}$ \\
\hline DMF & $\mathrm{S}$ \\
\hline DMSO & S \\
\hline Chlorobenzene & $\mathrm{S}$ \\
\hline Benzene & $\mathrm{S}$ \\
\hline Hexane & I \\
\hline Cyclohexane & I \\
\hline$n$-Heptane & I \\
\hline Methanol & I \\
\hline Ethanol & I \\
\hline Toluene & $\mathrm{G}(5.0)$ \\
\hline Ethylbenzene & $\mathrm{G}(2.8)$ \\
\hline Toluene/Cyclohexane (2/1, v/v) & $\mathrm{G}(3.6)$ \\
\hline Toluene/n-Heptane (3/1, v/v) & $\mathrm{G}(3.3)$ \\
\hline
\end{tabular}

a) S: soluble; I: insoluble; G: gel; P: precipitate. CGC: critical gelation concentration $(\mathrm{mmol} / \mathrm{L})$.

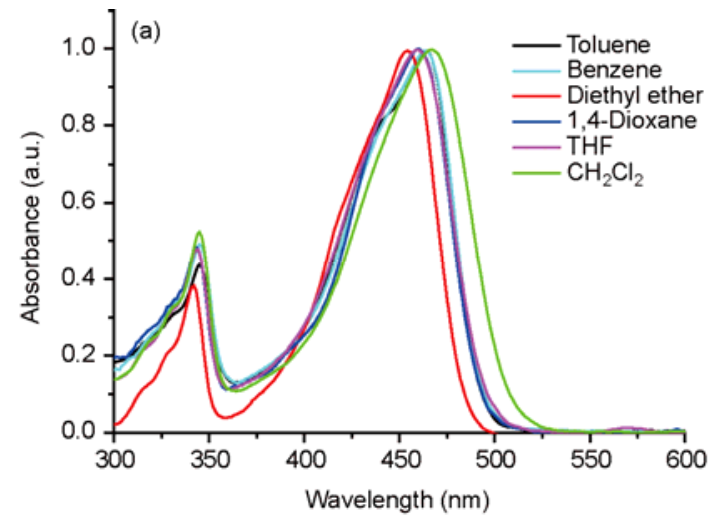

in toluene was due to the electronic transitions of carbazole unit, and the band at $463 \mathrm{~nm}$ might partly be ascribed to the charge-transfer (CT) transitions since it red- shifted gradually with increasing the polarity of the solvents. For example, it reached $470 \mathrm{~nm}$ in $\mathrm{CH}_{2} \mathrm{Cl}_{2}$. The CT state is generally sensitive to the exoteric microenvironment, so the fluorescent emission of $\mathbf{1}$ might be tuned by the polarity of the solvent. From Figure 1(b), it was clear that the emission bands became broad and red-shifted significantly with increasing the polarity of the solvent. For example, the emission maximum of 1 exhibited a remarkable red-shift of $61 \mathrm{~nm}$ from toluene (498 nm) to $\mathrm{CH}_{2} \mathrm{Cl}_{2}(559 \mathrm{~nm})$. Such distinct red-shift and broadening of the emission in polar solvents indicated an ICT (intramolecular charge transfer) character for the excited state [25,28].

\subsection{Self-assembly of 1 in gel phase}

The morphologies of the self-assemblies of $\mathbf{1}$ in gel state was investigated by SEM as shown in Figure 2. We could find 3D networks consisting of numerous intertwined fibers with diameter of 200-300 nm and length of several $\mu \mathrm{m}$ (Figure 2(a)) in the xerogel obtained from ethylbenzene.

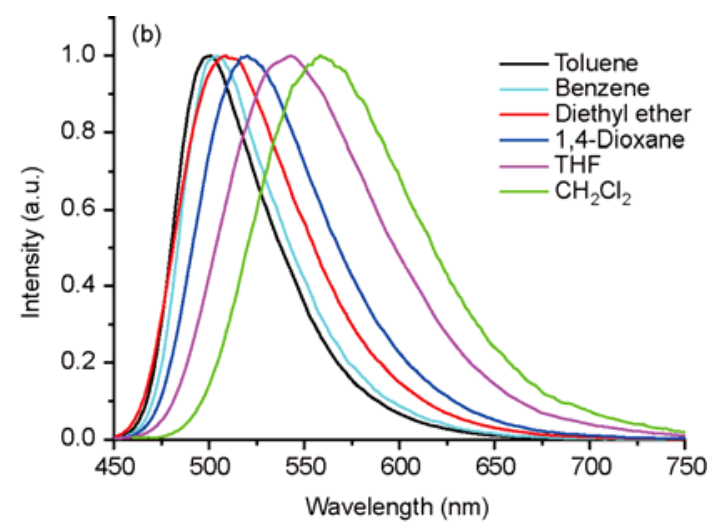

Figure 1 The normalized UV-Vis absorption (a) and PL (b) spectra of 1 in different solvents $\left(5.0 \times 10^{-6} \mathrm{~mol} / \mathrm{L}\right)$.
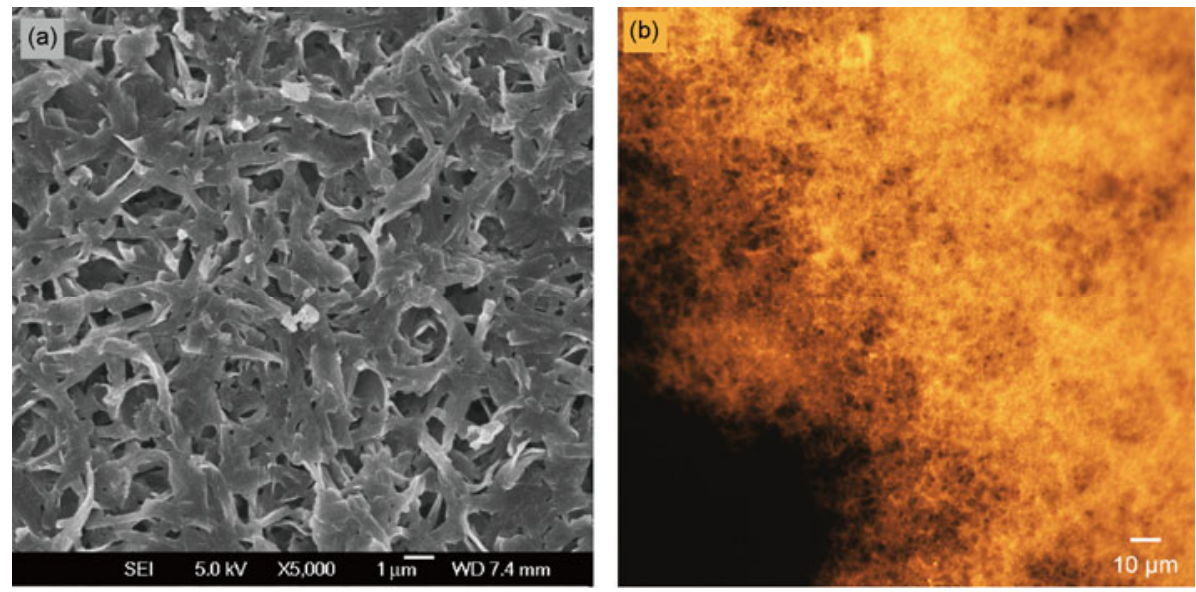

Figure 2 SEM (a) and fluorescence microscopy ( (b), $\lambda_{\mathrm{ex}}=510-550 \mathrm{~nm}$ ) images of the xerogel obtained from ethylbenzene. 
In order to obtain the information on the organization of fluorophores during the self-assembling, the time-dependent UV/Vis absorption spectra of $\mathbf{1}$ in ethylbenzene $\left(3.0 \times 10^{-3}\right.$ $\mathrm{mol} / \mathrm{L}$ ) were measured via ultrasound treatment followed by aging for a certain time (Figure 3). After a brief sonification, the solution of $\mathbf{1}$ begins to transform into gel. We could find that the absorption band at 343 and $455 \mathrm{~nm}$ appeared in solution red-shifted to 345 and $462 \mathrm{~nm}$ and decreased gradually in gel state. Meanwhile, a new band emerged at 500 $\mathrm{nm}$, which increased gradually during the gelation process, indicating the formation of J-aggregates $\mathbf{1}$ in the gel state [34]. We also found that the sol-gel transition was reversible, and the absorption maximum could blue-shift back to 455 $\mathrm{nm}$ when the gel was destroyed into the solution by heating. On the other hand, in the xerogel-based film the maximal absorption of 1 further red-shifted to $478 \mathrm{~nm}$ (Figure 4), suggesting J-aggregates $\mathbf{1}$ existed in the organogel nanofibers-based films. Figure 3(b) showed the time-dependent emission spectra of $\mathbf{1}$ upon aging the solution in ethylbenzene $\left(3.0 \times 10^{-3} \mathrm{~mol} / \mathrm{L}\right)$ after ultrasound stimulation. In solution, 1 could emit strong orange light (inset of Figure 3(b)) with an emission centered at $580 \mathrm{~nm}$. Upon the gel formation,
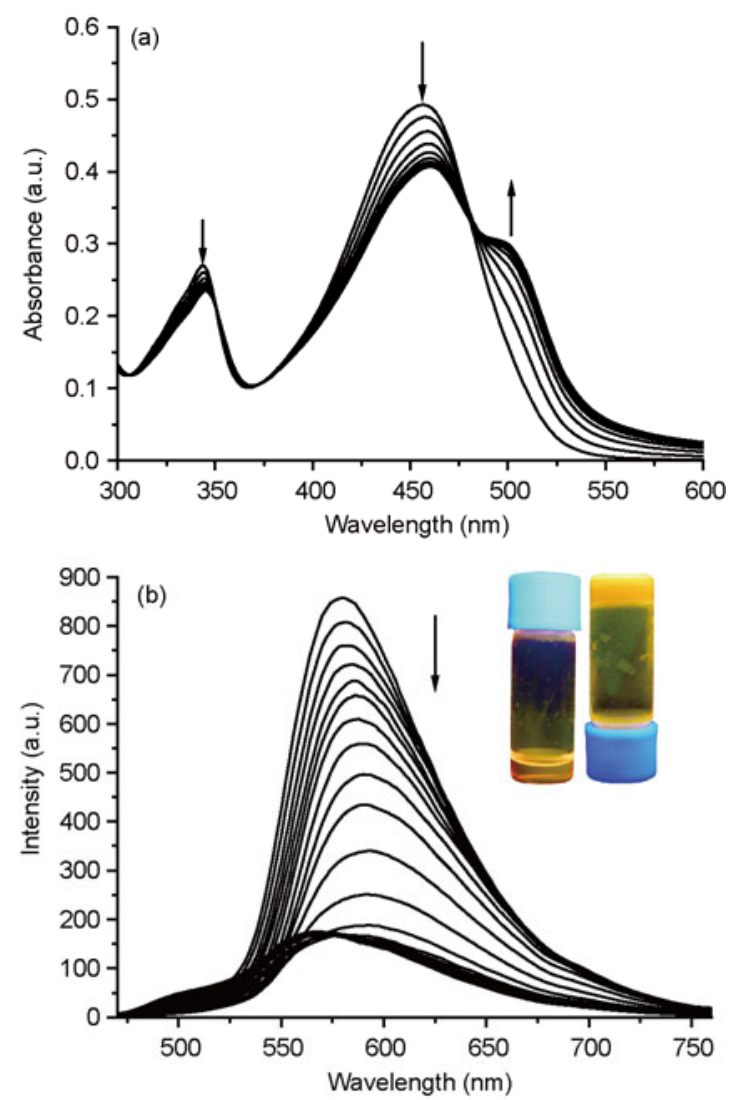

Figure 3 Time-dependent UV/Vis absorption (a) and fluorescence (b) spectra $\left(\lambda_{\mathrm{ex}}=462 \mathrm{~nm}\right)$ of 1 upon aging the solution in ethylbenzene $(3.0 \times$ $10^{-3} \mathrm{~mol} / \mathrm{L}$ ) after ultrasound treatment. The arrows indicate the spectral changes from the solution to gel. Inset: photographs of $1\left(6.0 \times 10^{-3} \mathrm{~mol} / \mathrm{L}\right)$ in solution (left vial) and in gel state (right vial) in ethylbenzene upon irradiation at $365 \mathrm{~nm}$.

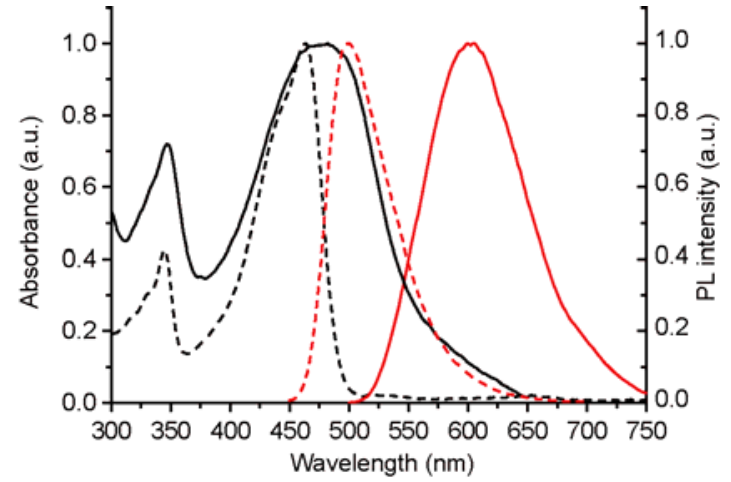

Figure 4 The normalized UV/Vis absorption (black) and fluorescence (red, $\left.\lambda_{\mathrm{ex}}=464 \mathrm{~nm}\right)$ spectra of 1 in ethylbenzene $\left(5 \times 10^{-6} \mathrm{~mol} / \mathrm{L}\right.$, dashed $)$ and in xerogel-based film casted on quartz slide (solid).

the emission red-shifted to $595 \mathrm{~nm}$, accompanying with a decrease of the fluorescent intensity. However, after a certain time, the emission at $595 \mathrm{~nm}$ for gel $\mathbf{1}$ blue-shifted to $568 \mathrm{~nm}$ gradually, accompanying with a slight increase of the fluorescent intensity. This blue shift might results from the TICT excited state was suppressed due to the inhibition of the conformation rotation in the gel phase, in which the molecules were packed into ordered superstructures [35]. It should be noted that the organogel of $\mathbf{1}$ still exhibited obvious orange emission (inset of Figure 3(b)). Whereas, the emission band red-shifted to $600 \mathrm{~nm}$ in the xerogel-based film (Figure 4), which could emit intense orange light as shown in the fluorescence microscopy (Figure 2(b)).

Figure 5(a) showed the XRD pattern of the xerogel of 1 obtained from ethylbenzene. In the small-angle region, we could find two strong narrow diffraction peaks corresponding to $d$-spacing of 2.53 and $1.27 \mathrm{~nm}$, which were close to a ratio of $1: 1 / 2$. It indicated a lamellar organization within the aggregates of 1 with an interlayer distance of $2.53 \mathrm{~nm}$. To reveal the molecular packing model, the optimized configurations of 1 was evaluated by the semiempirical (AM1) calculations. As a result, the extended width of $\mathbf{1}$ was calculated to be $2.53 \mathrm{~nm}$, which was in accordance with the period obtained from the XRD result. Figure 5(b) illustrated the proposed molecular packing model in xerogel $\mathbf{1}$.

\subsection{Nanofibers-based film for detecting organic amine vapors}

In our previous reports, we found that the emitting nanofibers-based film fabricated from $\beta$-diketonate boron complexes could sense amine vapors efficiently, the sensory properties of the obtained organogel nanofibers-based film $\mathbf{1}$ for detecting amines were investigated. As shown in Figure 6(a), upon exposed to the saturated vapor of aniline $(880$ $\mathrm{mL} / \mathrm{m}^{3}$ ) for $5 \mathrm{~s}$, the fluorescence of the nanofibers-based film was quenched by almost $90 \%$. The obvious fluorescence quenching of the nanofibers-based film was also observed for many kinds of volatile organic amines, such as $n$-butylamine, dibutylamine, diethylamine, triethylamine, cyclohexylamine 


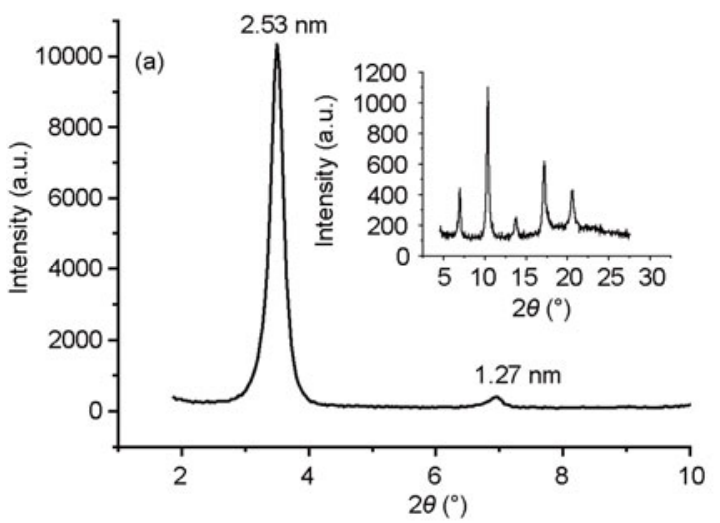

(b)

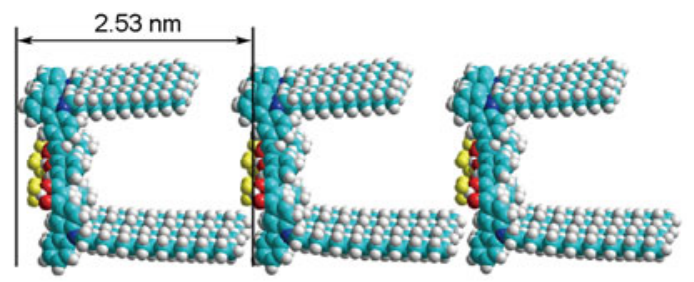

Figure 5 (a) X-ray diffraction pattern of the xerogel of $\mathbf{1}$ deposited on glass; (b) schematic illustration of the layered structures with the period of $2.53 \mathrm{~nm}$ in the gel of $\mathbf{1}$.

and pyridine. However, the other common reagents, such as hexane, toluene, acetonitrile, ethanol, acetone, chloroform, tetrahydrofuran, acetic acid and diethyl ether, could not lead to the fluorescence quenching of the nanofibers. The fluorescence quenching efficiency of the nanofibers-based film exposed to amines and some common reagents at 880 $\mathrm{mL} / \mathrm{m}^{3}$ for $5 \mathrm{~s}$ were shown in Figure 6(b). As a result, the nanofibers based on compound 1 could sense volatile organic amines and pyridine selectively and sensitively.

Figure 6(c) shows the plot of the emission intensity at
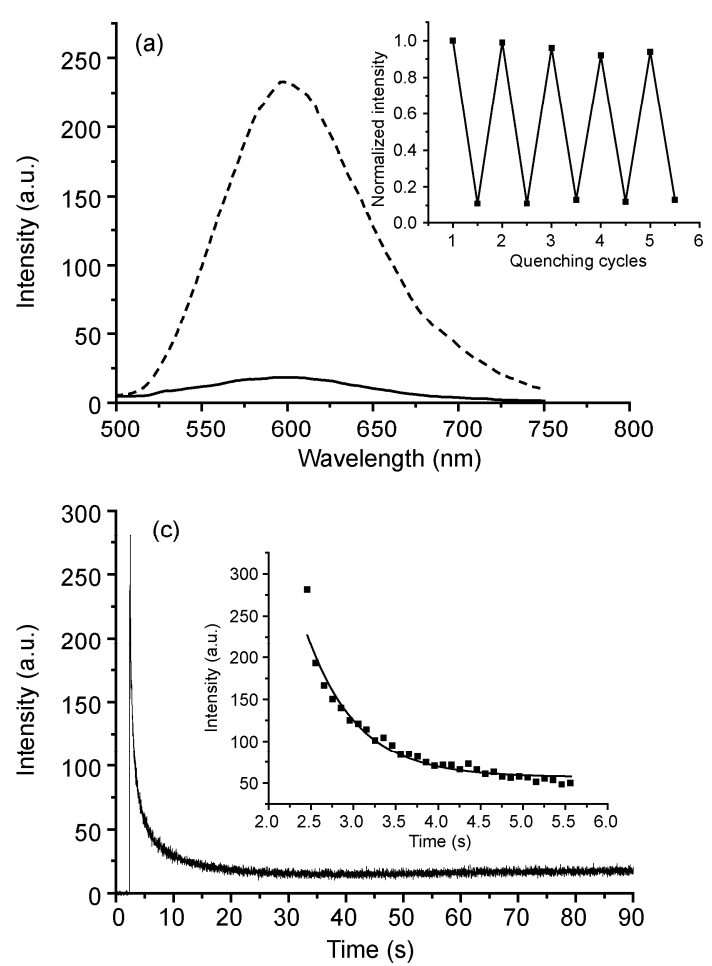

$600 \mathrm{~nm}$ of the film vs the exposure time to the saturated vapor of aniline. By fitting the intensity decay into a single exponential kinetics, we can deduce the response time of $0.59 \mathrm{~s}$ for the quenching process. In order to quantitatively describe the relationship between the quenching efficiency and the concentration, the changes of the emission intensity at $600 \mathrm{~nm}$ after repetitious injection of aniline vapor were recorded. As shown in Figure 6(d), a good linear relationship between the quenching efficiencies and the concentration was detected when the concentration of aniline vapor
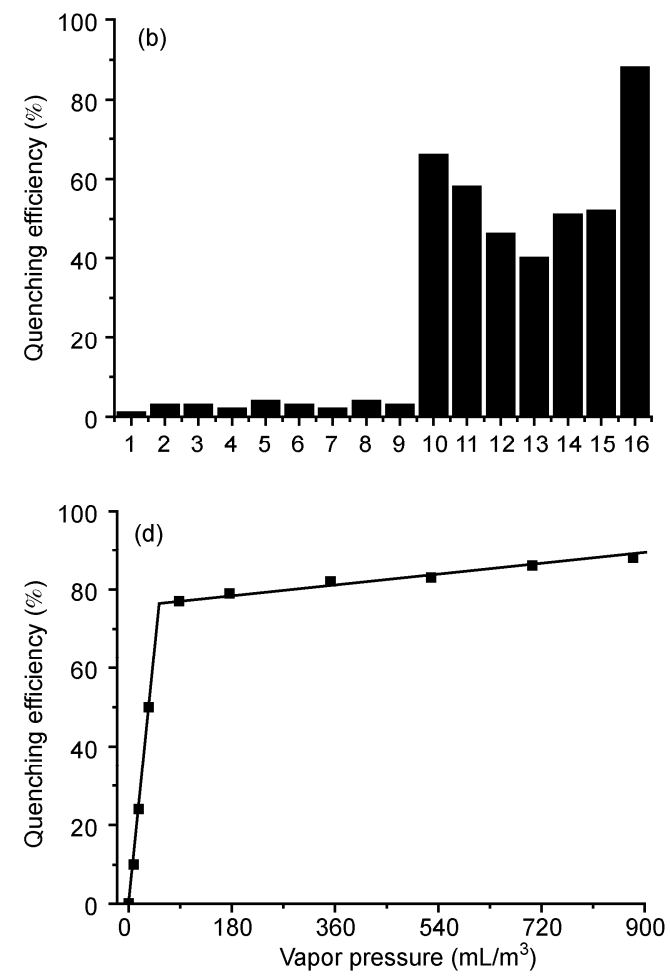

Figure 6 (a) Fluorescence spectra of the nanofibers-based film formed from compound $\mathbf{1}$ before (dashed) and after (solid) exposure to the saturated vapor of aniline $\left(880 \mathrm{~mL} / \mathrm{m}^{3}\right)$ for $5 \mathrm{~s}$. (b) Fluorescence response of the nanofiber-based film from 1 upon exposed to amines and some common reagents at 880 $\mathrm{mL} / \mathrm{m}^{3}$ for $5 \mathrm{~s}$ : 1 , hexane; 2 , toluene; 3 , acetonitrile; 4, ethanol; 5, acetone; 6 , chloroform; 7, tetrahydrofuran; 8 , acetic acid; 9 , diethyl ether; $10, n$-butylamine; 11, dibutylamine; 12, diethylamine; 13 , triethylamine; 14 , cyclohexylamine; 15 , pyridine; 16, aniline. (c) Time-course of fluorescence quenching of the film based on nanofibers of $\mathbf{1}$ after been added into the cell filled with the saturated vapor of aniline $\left(880 \mathrm{~mL} / \mathrm{m}^{3}\right)$, indicating a response time of about $0.59 \mathrm{~s}$. The intensity was monitored at $600 \mathrm{~nm}$. (d) The concentration-dependent fluorescence quenching efficiency of the film based on nanofibers of 1 exposed to the vapor of aniline for $5 \mathrm{~s}$. 
was below $88 \mathrm{~mL} / \mathrm{m}^{3}$. Considering the fact that a wellcalibrated photodetector can detect the intensity change as small as $0.1 \%$ or below, we suggested that the detection limit of nanofibers-based film was as low as $0.83 \mathrm{~mL} / \mathrm{m}^{3}$ for aniline vapor. The high sensitivity and rapid sensing response of the nanofibers 1 towards gaseous amine might be originated from the high surface-to-volume ratio and large interspace in the 3D networks, which were set up from numerous organogel nanofibers. Such scaffold-like microstructures in the film would favor the enhanced adsorption, accumulation and diffusion of gaseous molecules. In addition, the amplified fluorescence quenching induced by enhanced intermolecular exciton diffusion along the long axis of 1D nanofibers was another reason for the high performance of the obtained sensory nanomaterial. Interestingly, the fluorescence of the nanofibers-based film can be recovered absolutely after the nonemissive film was exposed to atmosphere for ca. $10 \mathrm{~min}$ or blown by hair drier for $2 \mathrm{~min}$. As shown in the inset of Figure 6(a), we can find that the reversibility of chemosensor of the nanofibers-based film in detection of aniline is excellent. Therefore, such a reversible fluorescence response to amines facilitates the practical application of the sensing system.

\section{Conclusions}

In conclusion, we have synthesized a new organogelator based on carbazole functionalized $\beta$-diketone-boron difluoride 1, which can form gels in toluene, ethylbenzene and some mixed solvents. SEM image of the xerogel illustrates that scaffold-like 3D networks were set up from numerous nanofibers in diameter of 200-300 nm. Emitting J aggregates were formed in ethylbenzene gel $\mathbf{1}$, and the fluorescence of the nanofibers-based film can be quenched efficiently and rapidly upon exposed to the vapors of $n$-butylamine, dibutylamine, triethylamine, triethylamine, cyclohexylamine, aniline and pyridine, instead of other common reagents. Therefore, the nanofibers based on compound $\mathbf{1}$ could sense volatile organic amines and pyridine selectively. Notably, the response time of the nanofibers-based film to aniline vapor reached ca. $0.59 \mathrm{~s}$, and the detection limit was as low as ca. $0.83 \mathrm{~mL} / \mathrm{m}^{3}$. We provide a strategy to prepare efficient fluorescent sensory materials with scaffold-like 3D networks set up from nanofibers via organogelation of $\pi$-gelators.

This work was supported by the National Natural Science Foundation of China (51073068), the National Basic Research Program of China (2009CB939701), NSFC-JSPS Scientific Cooperation Program (21011140069), and the Open Project of State Key Laboratory of Supramolecular Structure and Materials (SKLSSM201203).

1 Aneja V P, Roelle P A, Murray G C, et al. Atmospheric nitrogen compounds II: Emissions, transport, transformation, deposition and assessment. Atmos Environ, 2001, 35: 1903-1911
2 Boeker P, Horner G, Rosler S. Monolithic sensor array based on a quartz microbalance transducer with enhanced sensitivity for monitoring agricultural emissions. Sens Actuators B, 2000, 70: 37-42

3 Draisci R, Giannetti L, Boria P, et al. Improved ion chromatography-integrated pulsed amperometric detection method for the evaluation of biogenic amines in food of vegetable or animal origin and in fermented foods. J Chromatogr A, 1998, 798: 109-116

4 Hernández-jover T, Izquierdo-pulido M, Veciana-nogués M T, et al. Biogenic amine and polyamine contents in meat and meat products. $\mathrm{J}$ Agric Food Chem, 1997, 45: 2098-2102

5 Veciana-nogués M T, Mariné-font A, Vidal-carou M C. Biogenic amines in fresh and canned tuna. Effects of canning on biogenic amine contents. J Agric Food Chem, 1997, 45: 4324-4328

6 Chen S, Mahadevan V, Zieve L. Volatile fatty acids in the breath of patients with cirrhosis of the liver. J Lab Clin Med, 1970, 75: 622627

7 Preti G, Labows J N, Kostelc J G, et al. Analysis of lung air from patients with bronchogenic carcinoma and controls using gas chromatography-mass spectrometry. J Chromatogr, 1988, 432: 1-11

8 Simenhoff M L, Burker J F, Saukkonen J J, et al. Biochemical profile or uremic breath. Engl J Med, 1977, 297: 132-135

9 Che Y K, Yang X M, Liu G L, et al. Ultrathin n-type organic nanoribbons with high photoconductivity and application in optoelectronic vapor sensing of explosives. J Am Chem Soc, 2010, 132: 5743-5750

10 Rao G S T, Rao D T. Gas sensitivity of $\mathrm{ZnO}$ based thick film sensor to $\mathrm{NH}_{3}$ at room temperature. Sens Actuators B, 1999, 55: 166-169

11 Dikovska A O, Atanasov P A, Andreev A T, et al. ZnO thin film on side polished optical fiber for gas sensing applications. Appl Surf Sci, 2007, 254: 1087-1090

12 Compton R G, Sanders G H W. Electrode Potentials. Oxford : Oxford University Press, 1996

13 Jiang B P, Guo D S, Liu Y. Reversible and selective sensing of aniline vapor by perylene-bridged bis(cyclodextrins) assembly. J Org Chem, 2011, 76: 6101-6107

14 Lee $\mathrm{H} \mathrm{Y}$, Song X L, Park $\mathrm{H}$, et al. Torsionally responsive $C_{3^{-}}$ symmetric azo dyes: Azo-hydrazone tautomerism, conformational switching, and application for chemical sensing. J Am Chem Soc, 2010, 132: 12133-12144

15 Tao S Y, Li G T, Yin J X. Fluorescent nanofibrous membranes for trace detection of TNT vapor. J Mater Chem, 2007, 17: 2730-2736

16 Aguilar A D, Forzani E S, Leright M, et al. A hybrid nanosensor for TNT vapor detection. Nano Lett, 2010, 10: 380-384

17 Che Y K, Yang X M, Loser S, et al. Expedient vapor probing of organic amines using fluorescent nanofibers fabricated from an n-type organic semiconductor. Nano Lett, 2008, 8: 2219-2223

18 Che Y K, Yang X M, Zhang Z X, et al. Ambient photodoping of p-type organic nanofibers: Highly efficient photoswitching and electrical vapor sensing of amines. Chem Commun, 2010, 46: 4127-4129

19 Körsten S, Mohr G J. Star-shaped tripodal chemosensors for the detection of aliphatic amines. Chem Eur J, 2011, 17: 969-975

20 Mohr G J, Citterio D, Demuth C, et al. Reversible chemical reactions as the basis for optical sensors used to detect amines, alcohols and humidity. J Mater Chem, 1999, 9: 2259-2264

21 Peng H N, Ding L P, Liu T H, et al. An ultrasensitive fluorescent sensing nanofilm for organic amines based on cholesterol-modified perylene bisimide. Chem Asian J, 2012, 7: 1576-1582

22 Nagai A, Kokado K, Nagata Y, et al. Highly intense fluorescent diarylboron diketonate. J Org Chem, 2008, 73: 8605-8607

23 Halik M, Wenseleers W, Grasso C, et al. Bis(dioxaborine) compounds with large two-photon cross sections, and their use in the photodeposition of silver. Chem Commun, 2003, 13: 1490-1491

24 Sun Y M, Rohde D, Liu Y Q, et al. A novel air-stable n-type organic semiconductor: 4,4'-bis[(6,6'-diphenyl)-2,2-difluoro-1,3,2-dioxaborine] and its application in organic ambipolar field-effect transistors. J Mater Chem, 2006, 16: 4499-4503

25 Zhang X F, Lu R, Jia J H, et al. Organogel based on $\beta$-diketone-boron difluoride without alkyl chain and H-bonding unit directed by optimally balanced $\pi-\pi$ interaction. Chem Commun, 2010, 46: 8419-8421

26 Zhang X F, Liu X L, Lu R, et al. Fast detection of organic amine va- 
pors based on fluorescent nanofibers fabricated from triphenylamine functionalized $\beta$-diketone-boron difluoride. J Mater Chem, 2012, 22: 1167-1172

27 Liu X L, Xu D F, Lu R, et al. Luminescent organic 1D nanomaterials based on bis( $\beta$-diketone) carbazole derivatives. Chem Eur J, 2011, 17: 1660-1669

28 Liu X L, Zhang X F, Lu R, et al. Low-dimensional nanostructures fabricated from bis(dioxaborine)carbazole derivatives as fluorescent chemosensors for detecting organic amine vapors. J Mater Chem, 2011, 21: 8756-8765

29 Su L H, Bao C Y, Lu R, et al. Synthesis and self-assembly of dichalcone substituted carbazole-based low-molecular mass organogel. Org Biomol Chem, 2006, 4: 2591-2594

30 Xue P C, Lu R, Chen G J, et al. Functional organogel based on a sal- icylideneaniline derivative with enhanced fluorescence emission and photochromism. Chem Eur J, 2007, 13: 8231-8239

31 Chen P, Lu R, Xue P C, et al. Emission enhancement and chromism in a salen-based gel system. Langmuir, 2009, 25: 8395-8399

32 Yang J X, Tao X T, Yuan C X, et al. A facile synthesis and properties of multicarbazole molecules containing multiple vinylenebridges. J Am Chem Soc, 2005, 127: 3278-3279

33 Terech P, Weiss R G. Low molecular mass gelators of organic liquids and the properties of their gels. Chem Rev, 1997, 97: 3133-3159

34 Yang X C, Lu R, Xu T H, et al. Novel carbazole-based organogels modulated by tert-butyl moieties. Chem Commun, 2008, 4: 453-455

35 Yang X C, Lu R, Zhou H P, et al. Aggregation-induced blue shift of fluorescence emission due to suppression of TICT in a phenothiazine-based organogel. J Colloid Interf Sci, 2009, 339: 527-532

Open Access This article is distributed under the terms of the Creative Commons Attribution License which permits any use, distribution, and reproduction in any medium, provided the original author(s) and source are credited. 